\title{
Precise Muscle Selection Using Dynamic Polyelectromyography for Treatment of Post-stroke Dystonia: A Case Report
}

\author{
Tae Min Jung, MD', Ae Ryoung Kim, MD', Yoonju Lee, MD², \\ Dae-Hyun Kim, $\mathrm{MD}^{3}$, Deog Young Kim, MD, $\mathrm{PhD}^{1}$
}

\begin{abstract}
${ }^{1}$ Department of Rehabilitation Medicine and Research Institute of Rehabilitation Medicine, Yonsei University College of Medicine, Seoul; ${ }^{2}$ Department of Neurology, Yonsei University College of Medicine, Seoul; ${ }^{3}$ Department of Physical Medicine and Rehabilitation, Veterans Health Service Medical Center, Seoul, Korea
\end{abstract}

Dystonia has a wide range of causes, but treatment of dystonia is limited to minimizing the symptoms as there is yet no successful treatment for its cause. One of the optimal treatment methods for dystonia is chemodenervation using botulinum toxin type A (BTX-A), alcohol injection, etc., but its success depends on how precisely the dystonic muscle is selected. Here, we reported a successful experience in a 49-year-old post-stroke female patient who showed paroxysmal repetitive contractions involving the right leg, which may be of dystonic nature. BTX-A and alcohol were injected into the muscles which were identified by dynamic polyelectromyography. After injection, the dystonic muscle spasm, cramping pain, and the range of motion of the affected lower limb improved markedly, and she was able to walk independently indoors. In such a case, dynamic polyelectromyography may be a useful method for selecting the dominant dystonic muscles.

Keywords Dystonia, Botulinum toxins, Electromyography

\section{INTRODUCTION}

Dystonia is defined as an abnormal movement disorder characterized by sustained muscular contractions, frequently causing twisting and repetitive movements or abnormal postures [1]. Dystonia has a wide range of causes, but the treatment of dystonia has not been successful for its cause. Among the causes, the incidence of post-stroke dystonia is low, and lower limb dystonia accounts for a very small proportion of post-stroke dystonia cases especially [2].

Among the various treatment methods, botulinum toxin type A (BTX-A) injection has been introduced recently, but it is difficult to identify the dystonic muscles, and its

Received August 10, 2015; Accepted October 12, 2015

Corresponding author: Deog Young Kim

Department of Rehabilitation Medicine and Research Institute of Rehabilitation Medicine, Yonsei University College of Medicine, 50-1 Yonsei-ro, Seodaemun-gu, Seoul 03722, Korea. Tel: +82-2-2228-3714, Fax: +82-2-3463-7585, E-mail: kimdy@yuhs.ac

ORCID: Tae Min Jung (http://orcid.org/0000-0003-1391-7873); Ae Ryoung Kim (http://orcid.org/0000-0003-3765-3024); Yoonju Lee (http://orcid. org/0000-0002-3609-0285); Dae-Hyun Kim (http://orcid.org/0000-0002-5065-4286); Deog Young Kim (http://orcid.org/0000-0001-7622-6311).

(c) This is an open-access article distributed under the terms of the Creative Commons Attribution Non-Commercial License (http://creativecommons.org/ licenses/by-nc/4.0) which permits unrestricted noncommercial use, distribution, and reproduction in any medium, provided the original work is properly cited. Copyright ( 2016 by Korean Academy of Rehabilitation Medicine 
success may depend on the precision of muscle selection [3]. Various techniques including dynamic polyelectromyography, positron emission tomography-computed tomography (PET-CT), etc., have been suggested as useful techniques to identify which particular muscles contribute to dystonia [4]. Among them, dynamic polyelectromyography has obvious advantages because it not only identifies the particular contributions of offending muscles and their severity during a dystonic attack [5], but it also helps to determine the dosage of BTX-A. We reported a successful treatment experience in a rare poststroke dystonia patient with BTX-A and alcohol injection using dynamic polyelectromyography.

\section{CASE REPORT}

A 49-year-old woman presented with paroxysmal hypertonia and cramping pain in the right lower extremity which worsened at night for 2 months. She had suffered a right hemiplegia due to left middle cerebral artery infarction 5 months ago (Fig. 1). Thereafter, she could climb up and down stairs.

After dystonia developed, she suffered from serious deterioration of activities of daily living, because the hip and knee were severely flexed. Then, she was transferred to the Department of Rehabilitation Medicine, Yonsei University Hospital. She scored 53 points on the Modified Barthel Index (MBI). On initial physical examination, her right hip and knee were flexed and her ankle was slightly plantar flexed, and a claw toe deformity was also seen.
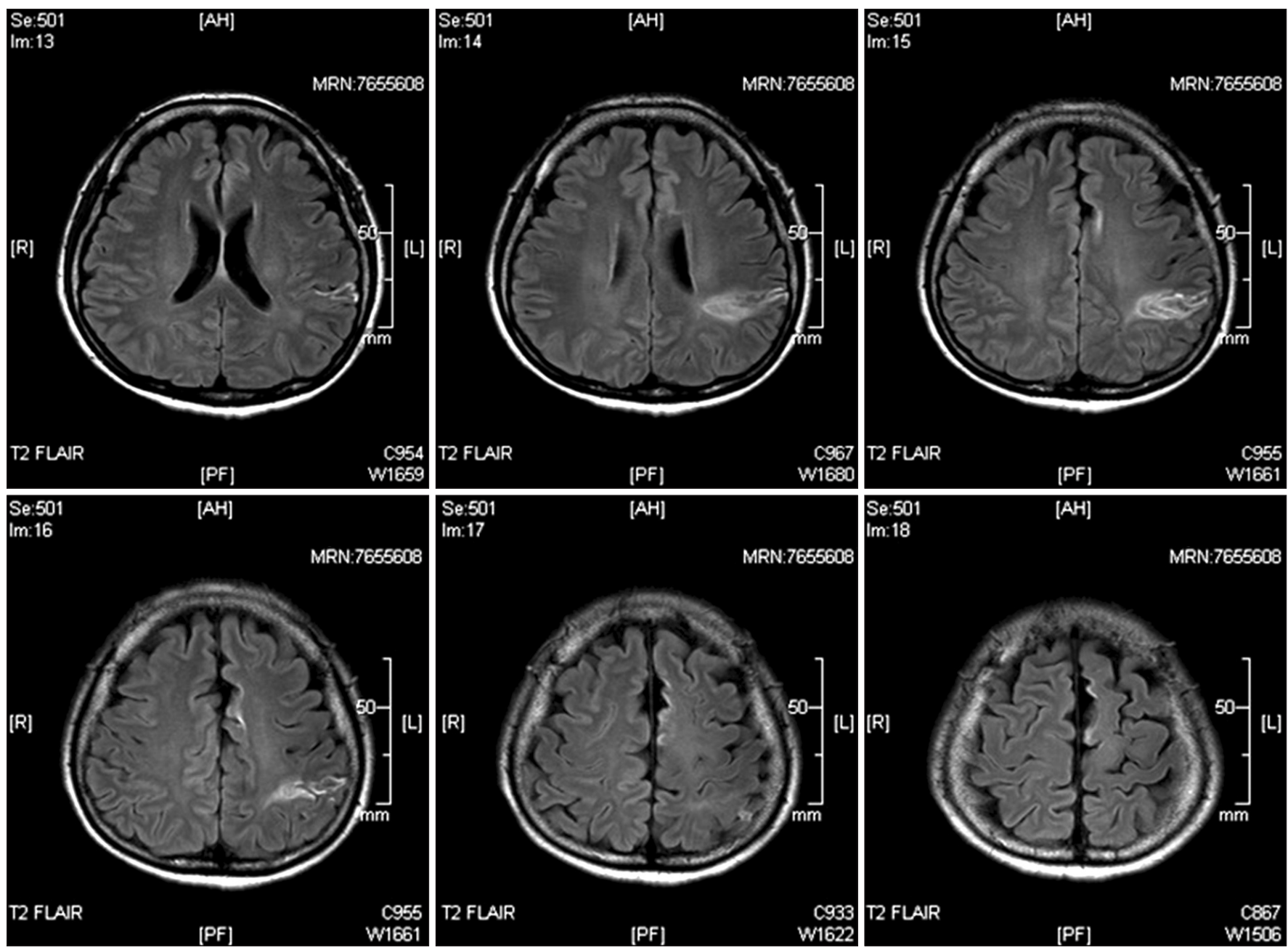

Fig. 1. Brain magnetic resonance imaging showed left middle cerebral artery infarction, involving the frontal and parietal lobes. 
The passive range of motion (ROM) was $-10^{\circ}$ for hip extension, $-50^{\circ}$ for knee extension, and $-10^{\circ}$ for ankle dorsiflexion. The Burke-Fahn-Marsden Dystonia Rating Scale (BFMDS) score was 16 points and the Unified Dystonia Rating Scale (UDRS) score was 32 points. The detailed clinical findings were presented in Table 1.

Table 1. Changes in muscle strength, ROM, and dystonia scale and pain in the right lower limb after injection

\begin{tabular}{|c|c|c|}
\hline & Before & After \\
\hline \multicolumn{3}{|l|}{ Manual muscle test } \\
\hline Hip flexor & Fair+ & Good \\
\hline Hip extensor & Fair+ & Good \\
\hline Knee flexor & UC & Fair \\
\hline Knee extensor & UC & Good \\
\hline Ankle dorsiflexor & UC & Trace \\
\hline Ankle plantar flexor & UC & Poor \\
\hline \multicolumn{3}{|l|}{ Passive ROM $\left({ }^{\circ}\right)$} \\
\hline Hip flexion & 120 & 120 \\
\hline Hip extension & -10 & 20 \\
\hline Knee flexion & 135 & 135 \\
\hline Knee extension & -50 & -10 \\
\hline Ankle dorsiflexion & -10 & 10 \\
\hline Ankle plantar flexion & 50 & 50 \\
\hline \multicolumn{3}{|l|}{ UDRS } \\
\hline Proximal leg & 16 & 0 \\
\hline Distal leg and foot & 16 & 0.5 \\
\hline \multicolumn{3}{|l|}{ BFMDS } \\
\hline Leg & 16 & 1 \\
\hline \multicolumn{3}{|l|}{ Visual analog scale } \\
\hline Right lower limb & 80 & 10 \\
\hline \multicolumn{3}{|l|}{ Modified Barthel Index } \\
\hline Personal Hygiene & 4 & 5 \\
\hline Bathing & 3 & 3 \\
\hline Feeding & 8 & 8 \\
\hline Toileting & 5 & 8 \\
\hline Stair climbing & 0 & 0 \\
\hline Dressing & 5 & 8 \\
\hline Bowel control & 10 & 10 \\
\hline Bladder control & 10 & 10 \\
\hline Ambulation & 0 & 3 \\
\hline Chair/bed transfer & 8 & 12 \\
\hline Total & 53 & 67 \\
\hline
\end{tabular}

ROM, range of motion; UDRS, Unified Dystonia Rating Scale; BFMDS, The Burke-Fahn-Marsden Dystonia Rating Scale; UC, uncheckable due to severe spasm.
She also complained of severe cramping pain with a visual analogue scale (VAS) score of 80 . We administered clonazepam $0.5 \mathrm{mg}$ and baclofen $30 \mathrm{mg}$ per day for 3 weeks, but they were not effective. Therefore, we decided to administer BTX-A and alcohol injection. To identify the dystonic muscles precisely, dynamic electromyographic activities of several suspected muscles in the right lower limb were recorded using Medelec Synergy EMG system (Oxford Instruments, Oxford, UK) during dystonia attack. With a 10-channel mode, electromyographic activities of all suspected muscles were recorded simultaneously in the supine position (Fig. 2). Disposable $50 \mathrm{~mm}$, 26-gauge monopolar needle electrodes (Natus Neurology, Middleton, WI, USA) as recording electrodes were placed on the target muscles based on the Anatomical Guide for the Electromyographer by Perotto, and $\mathrm{AgCl}$ surface reference electrode was placed over proximal side $4 \mathrm{~cm}$ from the recording electrodes. We found that right iliopsoas, biceps femoris long head (BFLH), semitendinosus, tibialis anterior (TA), flexor digitorum brevis (FDB), gastrocnemius (GCM) demonstrated greater overactivity than the other muscles during dystonia attack (Fig. 3). Based on these findings, total 400 IU of BTX-A (Botox; Allergan Inc., Irvine, CA, USA) were injected into the right iliopsoas (100 IU), BFLH (125 IU), semitendinosus (75 IU), TA (60 IU), and FDB (40 IU). The hypertonus of the right GCM was treated by motor point block using $50 \%$ alcohol.

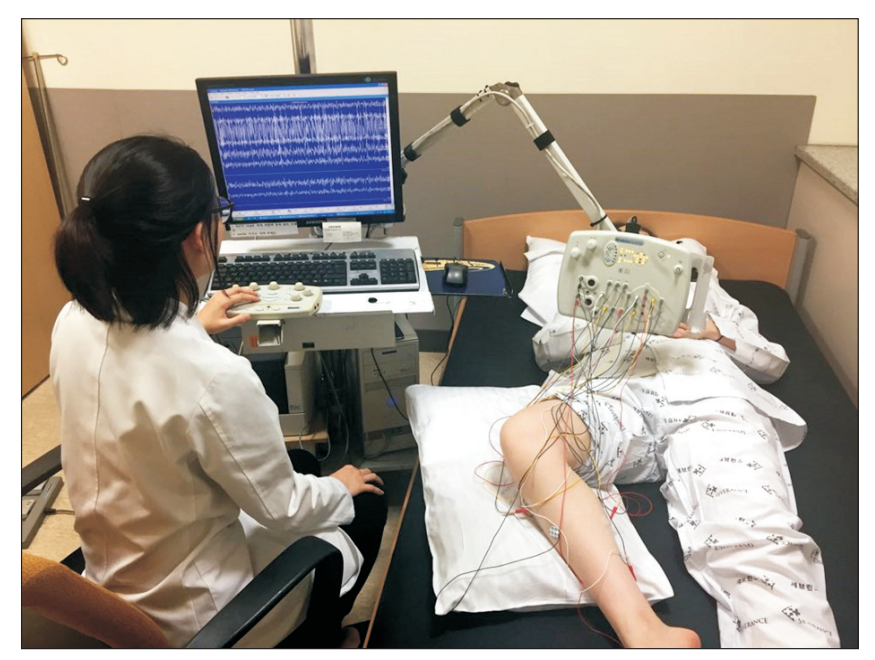

Fig. 2. Using the 10-channel electromyography mode, dynamic polyelectromyography was performed during the dystonic event. Motor unit action potentials of each lower extremity were recorded simultaneously. 
One week later, the dystonia events were decreased significantly in terms of frequency and she had better postures (Figs. 4, 5). She could stand independently, and her pain score was decreased from 80 to 10 on the VAS. In particular, sleep disturbance due to the dystonia event

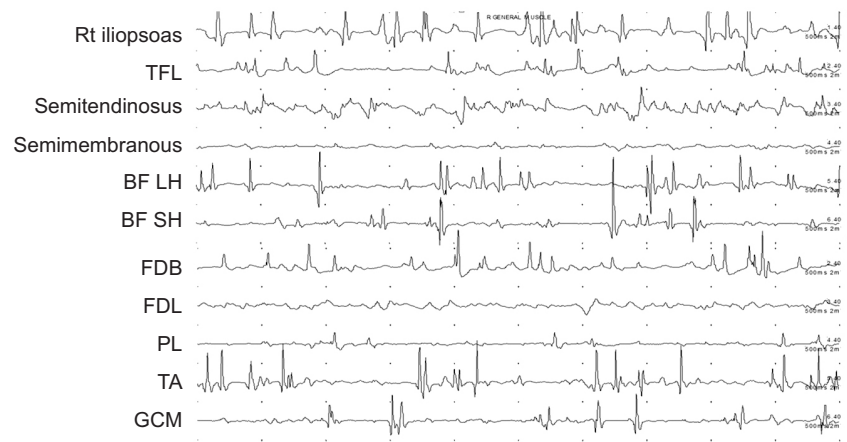

Fig. 3. Findings of dynamic polyelectromyography in the affected lower limb muscles at baseline. TFL, tensor fascia lata; BF LH, biceps femoris long head; BF SH, biceps femoris short head; FDB, flexor digitorum brevis; FDL, flexor digitorum longus; PL, peroneus longus; TA, tibialis anterior; GCM, gastrocnemius. did not occur after injection. BFMDS score decreased from 16 points to 1 point and UDRS score also decreased from 32 points to 0.5 points. The passive ROM was also improved (Table 1), 1 month after injection, the MBI score improved from 53 to 67 . Especially, the score for ambulation increased from 0 to 3 , and the score for transfer improved from 8 to 12 (Table 1). Intensive ROM exercise and gait training were preformed after the injection for 1 month. She was able to walk independently indoors, and return home.

\section{DISCUSSION}

Dystonia is a neurological movement disorder, in which sustained muscle contractions cause twisting and repetitive movements or abnormal postures [1]. To manage dystonia, many therapeutic approaches such as medication and deep brain stimulation have been introduced. Recently, chemical neurolysis using BTX has become popular for dealing with dystonic symptoms [6]. Especially, in some focal dystonic diseases such as blepharospasm and cervical dystonia, BTX injection is known to
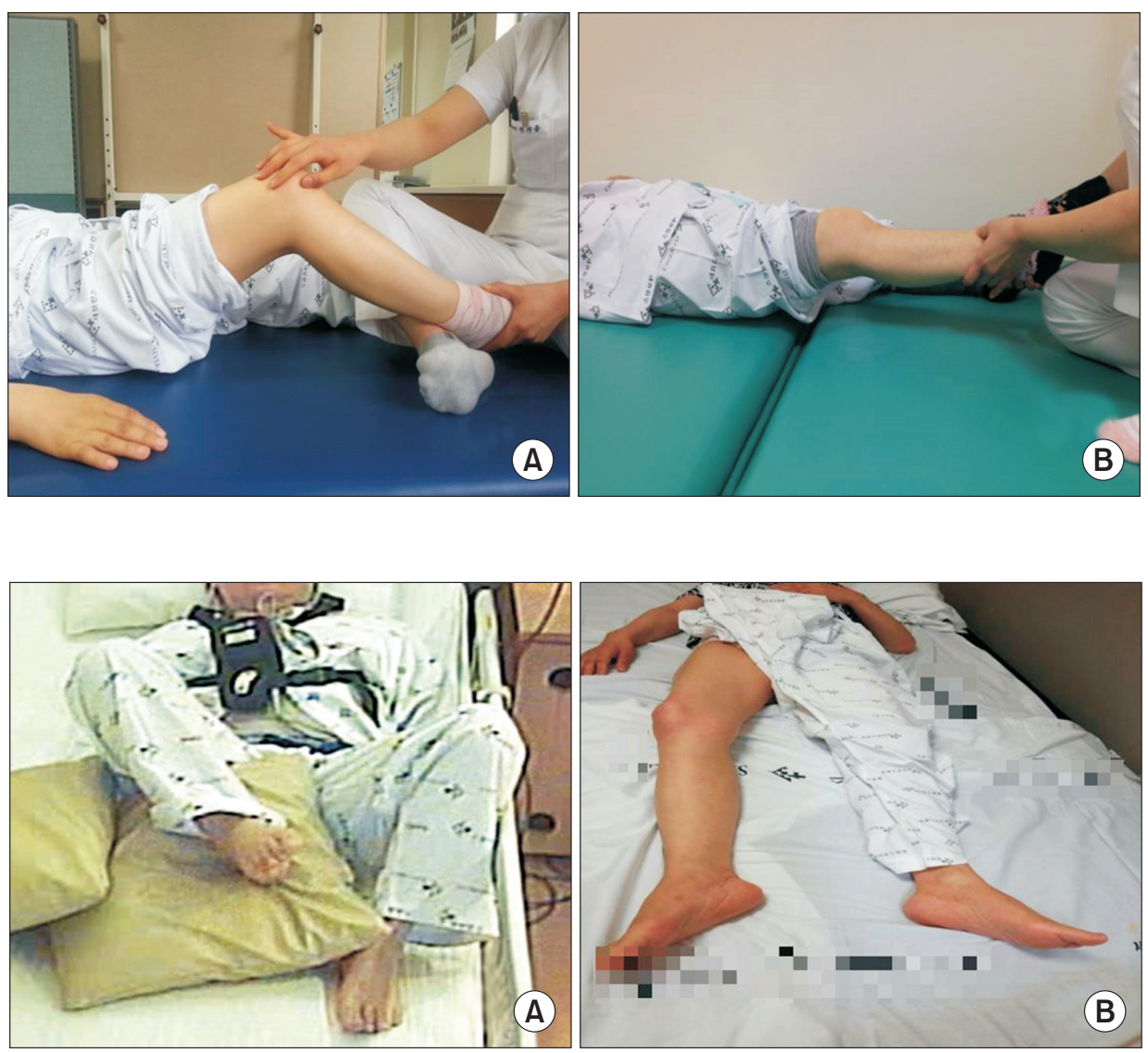

Fig. 4. Changes in the affected lower limb on a lateral view before injection (A); the knee flexor could not be extended by hand almost all day. (B) After injection, her knee could be extended to a near normal range.

Fig. 5. Changes in the affected lower limb on a superior view before injection (A); her right hip and knee flexor were hyperactive with severe muscle cramping pain. (B) After injection, the flexed posture and pain were remarkably decreased. 
be the most effective and safe treatment strategy [7]. Unfortunately, the gold standard for treatment of lower limb focal dystonia has not been established [8].

BTX injection was considered in this case because dystonia only involved the right leg and treatment with clonazepam and baclofen was ineffective.

Many researchers have shown that the most important determinant of a favorable response to BTX was a proper selection of the involved muscles [8]. Clinical observation is a common means to identify dystonic muscles at the pre-evaluation stage for BTX injection [4]. But it is difficult to apply it in some patients with severe hypertonia and to distinguish dystonic muscles from the contracture [9], and many muscles were clinically suspected to be dystonic muscles even though the same dystonic postures were observed because different combinations of muscle activation can lead to similar postural abnormalities [4]. This is in line with several studies, in which polymyographic electromyography revealed a different pattern of muscle involvement compared to that found during clinical evaluation [4]. Therefore, it was not easy to precisely identify dystonic muscles through clinical observation in this case. Also, a large amount of BTX over the maximal safe dose should not be injected according to clinical observation. Hence, some other methods to identify dystonic muscles precisely have been attempted in order to optimize the treatment response to BTX.

Polyelectromyography, PET-CT, and frequency analysis in electromyographic evaluation have been tried [4]. Comella et al. [10] reported that a significantly greater improvement was observed in the group using polyelectromyography compared to the group with clinical evaluation for selecting the dystonic muscles in a randomized controlled study of patients with cervical dystonia.

In this case, we thought that dynamic polyelectromyography may be more suitable than PET-CT. PET-CT is very expensive, radiation exposure is common, and the patient will not be able to tolerate the long scan time of the PET-CT machine. But dynamic polyelectromyography was useful for evaluating muscle activity over a relatively shorter time and it was easy to compare the muscles with clinical observation of movement simultaneously.
In the future, a more specific guideline for selection of dystonic muscles is required through further research.

\section{CONFLICT OF INTEREST}

No potential conflict of interest relevant to this article was reported.

\section{REFERENCES}

1. Fahn S. Concept and classification of dystonia. Adv Neurol 1988;50:1-8.

2. Alarcon F, Zijlmans JC, Duenas G, Cevallos N. Poststroke movement disorders: report of 56 patients. J Neurol Neurosurg Psychiatry 2004;75:1568-74.

3. Jankovic J. Treatment of cervical dystonia with botulinum toxin. Mov Disord 2004;19 Suppl 8:S109-15.

4. Nijmeijer SW, Koelman JH, Kamphuis DJ, Tijssen MA. Muscle selection for treatment of cervical dystonia with botulinum toxin: a systematic review. Parkinsonism Relat Disord 2012;18:731-6.

5. Esquenazi A, Cioni M, Mayer NH. Assessment of muscle overactivity and spasticity with dynamic polyelectromyography and motion analysis. Open Rehabil J 2010;3:143-8.

6. Steeves TD, Day L, Dykeman J, Jette N, Pringsheim T. The prevalence of primary dystonia: a systematic review and meta-analysis. Mov Disord 2012;27:1789-96.

7. Takeuchi N, Chuma T, Mano Y. Phenol block for cervical dystonia: effects and side effects. Arch Phys Med Rehabil 2004;85:1117-20.

8. Jankovic J. Medical treatment of dystonia. Mov Disord 2013;28:1001-12.

9. Peng Q, Park HS, Shah P, Wilson N, Ren Y, Wu YN, et al. Quantitative evaluations of ankle spasticity and stiffness in neurological disorders using manual spasticity evaluator. J Rehabil Res Dev 2011;48:473-81.

10. Comella CL, Buchman AS, Tanner CM, Brown-Toms NC, Goetz CG. Botulinum toxin injection for spasmodic torticollis: increased magnitude of benefit with electromyographic assistance. Neurology 1992;42:87882. 